\title{
ASOCIATIVIDAD PARA MEJORA DE LA COMPETITIVIDAD DE PEQUEÑOS PRODUCTORES AGRÍCOLAS
}

\author{
BUSINESS PARTNERSHIPS FOR IMPROVING THE COMPETITIVENESS OF SMALL \\ FARMERS
}

\author{
${ }^{1}$ Ampelio Ferrando Perea
}

\begin{abstract}
Resumen
La presente investigación tiene por objetivo identificar y analizar las formas de asociarse de los pequeños productores agrícolas del país que permiten mejorar su competitividad e inserción en los mercados nacionales e internacionales. Para lograr este objetivo la investigación se hizo mediante una encuesta a 100 pequeños productores agrícolas y se entrevistó a 11 representantes de los distintos tipos de formas de organización asociada empleadas por ellos, en los departamentos de: Ayacucho, Cuzco, Ica, Junín, Lambayeque, Lima, Piura y Tumbes. El análisis de los resultados llevan a la conclusión que la asociatividad de los pequeños productores agrícolas es un sistema de organización que posibilita mejorar la competitividad de los pequeños productores agrícolas y las formas de asociatividad predominantes son: la asociación, la cooperativa y las comunidades campesinas y nativas; ubicándose en segundo orden: las cadenas productivas y clusters, sociedades agrícolas de interés social, redes empresariales verticales y horizontales y uniones de ahorro y créditos.
\end{abstract}

Palabras claves: asociatividad, competitividad, productividad, cadena de valor, pequeño productor agrícola.

\begin{abstract}
This research aims to identify and analyze the forms of association of small farmers in the country that improve their competitiveness and integration into national and international markets. To achieve this goal the research was done through a survey of 100 small farmers and interviewed 11 representatives of different types of associated organizational forms employed by them, within the departments: Ayacucho, Cuzco, Ica, Junín, Lambayeque, Lima, Piura and Tumbes. The analysis of the results leads to the conclusion that the association of small agricultural producers is an organizational system that allows improving the competitiveness and the dominant forms of partnership are: association, cooperative and rural and native communities in reaching second-order clusters and productive chains, agricultural societies of social interest, vertical and horizontal business networks and savings and credit unions.
\end{abstract}

Key words: associativity, competitiveness, productivity, value chain, small farmer.

\section{Introducción}

Actualmente, el mayor desafío que enfrenta el Perú en cuanto a su inserción competitiva en la economía mundial es adaptar y transformar su tejido empresarial para responder a los cambios en el nuevo escenario comercial internacional $\mathrm{y}$, al mismo tiempo, asegurar un crecimiento de base amplia. La apertura del país a los mercados internacionales exige a las empresas a formular e implantar nuevas estrategias que les permitan desarrollar ventajas competitivas y lograr un mejor posicionamiento en los mercados globales. Es evidente que alcanzar este tipo de posicionamiento resulta una tarea bastante compleja, genera un costo y se torna difícil para un gran número de empresas, mucho más si se trata de pequeños productores agrícolas, ya que estos generalmente presentan debilidades que les lleva a la pérdida de oportunidades de negocios que garanticen su sostenibilidad y desarrollo futuro. En tal situación, la asociatividad para la competitividad es un tema muy importante en el desarrollo de las micro y pequeñas empresas agrícolas en el Perú, la cual requiere en gran medida de la promoción, coordinación, concertación y validación con los diferentes actores involucrados en el proceso, así como evaluar la ejecución de los diferentes programas y proyectos contemplados en la estrategias de asociatividad en las políticas de apoyo a los pequeños agricultores. La competitividad debe ser entendida como la capacidad que tiene una organización, pública o privada, lucrativa o no, de obtener y mantener ventajas competitivas que le permitan alcanzar, sostener y mejorar una determinada posición en el entorno socioeconómico. La ventaja competitiva de una empresa está en su habilidad, recursos, conocimientos y atributos de los que dispone, y los mismos de los que carecen sus competidores o tienen en menor medida, haciendo posible la obtención de unos rendimientos superiores a los de aquellos. (Porter, 1991). 
Con tal propósito de lograr ventaja competitiva, una organización debe desarrollar funciones de creación de valor a un costo menor que el de sus rivales o desarrollarlas de manera que genere diferenciación y un precio superior. Ello le permitirá alcanzar grados superiores en eficiencia, calidad, innovación y capacidad de satisfacer al cliente. (Hill, 2009).

Numerosos especialistas remarcan la necesidad de propiciar la asociatividad agraria como medida para impulsar el desarrollo de la agricultura del país, en particular la pequeña agricultura haciéndola competitiva. Esto, debido a que uno de los más importantes problemas que enfrenta la pequeña agricultura peruana para lograr un desarrollo sostenible que le permita insertarse en los mercados nacionales e internacionales en forma exitosa es el minifundio. Según el IV Censo Agropecuario 2012, se tiene que de 2'213,506 unidades agropecuarias, 1'810,962 (81.81\%) poseen tierras entre 0.1 a 5 hectáreas y 195,652 (8.84\%) de 5.1. a 10 hectáreas. (INEI,2013). Ver Tabla 1 siguiente.

Tabla 1. Número de unidades agropecuarias por tamaño.

\begin{tabular}{ccccccc}
\hline De $0.1 \mathrm{a}$ & De $5.1 \mathrm{a}$ & De $10.1 \mathrm{a}$ & De $20.1 \mathrm{a}$ & De $50.1 \mathrm{a}$ & De $100.1 \mathrm{Ha}$ & \multirow{2}{*}{ Total } \\
$5 \mathrm{Ha}$ & $10 \mathrm{Ha}$ & $20 \mathrm{Ha}$ & $50 \mathrm{Ha}$ & $100 \mathrm{Ha}$ & a más & \\
\hline 1810962 & 195652 & 99872 & 65249 & 20754 & 21017 & 2213506 \\
$81.81 \%$ & $8.84 \%$ & $4.51 \%$ & $2.95 \%$ & $0.94 \%$ & $0.95 \%$ & $100 \%$ \\
\hline
\end{tabular}

Solo Unidades Agropecuarias con tierras.

Fuente: Instituto Nacional de Estadística e Informática - IV Censo Nacional Agropecuario 2012

Esta excesiva parcelación de la tierra dificulta la adopción de tecnologías, encarece la adquisición de insumos, incrementa el costo de los créditos, disminuye el poder de negociación a los pequeños productores agrícolas frente a los intermediarios comercializadores generando precios más bajos por sus productos; y dificulta el acceso a los mercados nacionales e internacionales, que requieren de volúmenes y niveles de estandarización de los productos que generalmente no pueden lograr los pequeños agricultores. La apertura del país a los mercados internacionales exige a las empresas a formular e implantar nuevas estrategias que les permitan desarrollar ventajas competitivas y lograr un mejor posicionamiento en los mercados globales. Por otro lado, los pequeños productores agrícolas prefieren trabajar de modo individual y no en asociación, se enfoca a cubrir los pequeños mercados locales, sin la posibilidad de alcanzar los beneficios de la economía de escala en el volumen de su producción para cubrir los costos fijos de incurrir en mercados más amplios como los internacionales.

La asociatividad se concibe como una unión voluntaria de personas que se articulan para llevar a cabo acciones conjuntas en pro de alcanzar objetivos comunes que no podrían lograr individualmente. En este sentido, la asociatividad para mejorar el negocio agrícola supone el protagonismo de los productores y productoras y también un fuerte compromiso de las instituciones de apoyo para garantizar asistencia técnica, capacitación, servicios de información y comercialización y financiamiento. (CENTA,2002). Por consiguiente, para lograr y mejorar la competitividad de los pequeños productores agrícolas rurales se hace necesario determinar formas apropiadas de asociatividad, brindándoles la asesoría y los apoyos necesarios para que puedan lograr un efectivo proceso de internacionalización, consolidando su oferta exportable e inserción en los mercados internacionales. Por consiguiente, en la presente investigación se analizan las principales formas de asociatividad para la competitividad de los pequeños productores agrícolas que se vienen aplicando en la práctica en el país, las cuales pueden ser utilizadas de manera más intensa en todas las regiones para lograr el objetivo de mejorar la competitividad de estos productores agrícolas en el Perú.

El objetivo general de la investigación es identificar y analizar las formas de asociatividad de los pequeños productores agrícolas del país que permiten mejorar su competitividad e inserción en los mercados nacionales e internacionales. Este objetivo general se desglosa en los siguientes objetivos específicos: a) evaluar las actividades de la cadena de valor de los pequeños productores agrícolas, b) determinar factores que favorecen la asociatividad de los pequeños productores agrícolas, c) determinar factores que dificultan la asociatividad de los pequeños productores agrícolas y d) Compilar experiencias exitosas de asociatividad de pequeños productores agrícolas.

\section{Materiales y métodos}

Tipo de la investigación. La presente investigación ha seguido las pautas de tipo descriptivo, ya que describe los diversos hechos en la realidad problemática de la asociatividad y competitividad de los pequeños productores agrícolas, las mismas que se constituyeron en las causas incidentes que motivaron la necesidad de desarrollar la presente investigación.

Diseño de la investigación. La presente investigación es de diseño no experimental seccional transversal pues se investigó la situación de la asociatividad y competitividad de los pequeños productores agrícolas en un momento determinado de tiempo.

Población y muestra. Se realizó una encuesta a una muestra de 100 pequeños productores agrícolas y entrevistó a representantes de 11 organizaciones de las 
principales formas de asociación de los departamentos de: Ayacucho, Cuzco, Ica, Junín, Lambayeque, Lima, Piura y Tumbes. La muestra fue calculada con $95.5 \%$ de confianza y un margen de error del $10 \%$, de una población mayor de 100,000 sujetos.

Limitaciones del estudio. Este trabajo de investigación presenta varias limitaciones:

La primera limitación es el lugar, se realizó únicamente en los departamentos de Ayacucho, Cuzco, Ica, Junín, Lambayeque, Lima, Piura y Tumbes.

Lasegunda limitación fue el tipo departicipantes. El estudio se limitó a una encuesta de solo 100 pequeños productores y entrevistas a 11 dirigentes de las organizaciones y 2 expertos en el tema de la asociatividad empresarial agrícola, que gentilmente estuvieron dispuestos a colaborar con la realización del estudio. Asimismo, participaron como encuestadores y entrevistadores 5 estudiantes de la Maestría en Agronegocios. Ha sido también una limitación importante la disponibilidad de recursos financieros para la investigación proporcionados por los fondos asignados del FEDU.

\section{Resultados y discusión}

\section{Resultados}

Formas asociativas de pequeños productores agrícolas. Las alternativas legales para la organización agrícola son: Empresa Individual de Responsabilidad LimitadaEIRL, Sociedad Anónima-SA, Sociedad Anónima Cerrada-SAC, Sociedad Comercial de Responsabilidad Limitada- SCRL, Asociación Civil sin fines de lucro, Cooperativa, Comité y Fundación. De estas, la EIRL sólo sirve para negocios individuales, o sea, de una sola persona; es un modelo jurídico que no se pueda usar para una organización. De igual forma, la SCRL y la SAC son modelos que no permiten incorporar a más de 20 personas, lo que las hace inútiles para organizar a pequeños agricultores que normalmente buscan sumar fuerzas y unir a gran cantidad de personas. Por último, cabe aclarar que tanto el Comité como la Fundación son modelos jurídicos orientados a la recolección o gestión de fondos de carácter social o benéfico. De esta manera, considerando estos modelos como descartados, quedan como alternativas posibles de organización la Sociedad Anónima, la Asociación y la Cooperativa.

Por otro lado, en el Perú se vienen llevando a cabo diversas formas de cooperación entre las empresas. Estas formas de asociatividad empresarial son: cadenas productivas, comunidades campesinas y nativas, clúster o conglomerado, unión de ahorro y crédito-UNICA, empresa de accionariado campesino-EAC, entidad asociativa agraria-EAA, sociedad agrícola de interés social-SAIS; redes empresariales: verticales: desarrollo de proveedores y horizontales: consorcios.

Un breve análisis con los aspectos centrales de cada una de ellas se presenta a continuación:
La Asociación civil: Es una persona jurídica de derecho privado, sin fines de lucro. Al crearse la Asociación se establece su fin, el cual no es obtener lucro. El fin de una Asociación Civil puede ser: gremial, cultural, educativo, beneficencia, asistencia social, científico, artístico, literario, deportivo, político y de vivienda. Todas las actividades que realiza la Asociación obedecen al fin estipulado. No hay límite en el número de asociados, salvo disposición en contrario del estatuto.

Cooperativa: Es una persona jurídica de derecho privado, con un régimen legal propio. La tierra de los productores pasa a ser propiedad de la Cooperativa y los excedentes provenientes de las venta realizadas por la Cooperativa se reparten entre los asociados, pudiendo preverse diversas formas para ejecutar esto. Las cooperativas se rigen por el Decreto Supremo $\mathrm{N}^{\circ}$ 070-90-TR: Ley general de cooperativas. Desde el año 2012, La ley $\mathrm{N}^{\circ}$ 29972" Ley que promueve la inclusión de los productores agrarios a través de las cooperativas" favorece a los pequeños productores agrícolas, ya que en su artículo $1^{\circ}$ establece: "la presente ley tiene por objeto regular el marco normativo para la inclusión de los productores agrarios a través de las cooperativas, mejorando su capacidad de negociación y generando economías de escala, permitiéndoles insertarse competitivamente en el mercado".

Cadenas productivas: Son asociaciones de unidades familiares cuya finalidad es producir bienes o servicios determinados. Cuentan con una organización temporal que comprende una Asamblea General y un Consejo de Coordinación, el cual incluye un coordinador productivo y de finanzas, uno de logística y otro de post-cosecha y comercialización. El grupo lleva libros de actas y otros registros. Los bienes y servicios producidos por estas cadenas cuentan con un mercado garantizado a través de un contrato con medianos y grandes empresarios posicionados en el mercado.

Clusters o conglomerados: Un clúster se define como un conjunto o grupo de empresas pertenecientes a diversos sectores, ubicadas en una zona geográfica limitada, interrelacionadas mutuamente en los sentidos vertical, horizontal y colateral en torno a unos mercados, tecnologías y capitales productivos que constituyen núcleos dinámicos del sector industrial, formando un sistema interactivo en el que, con el apoyo decidido de la Administración, pueden mejorar su competitividad. La formación de los clusters permite generar economías de aglomeración y de integración funcional. A través de ellos se busca tener ventaja competitiva sustentable y generar mayor valor_agregado.

Comunidades campesinas y nativas: Las Comunidades Campesinas son organizaciones de interés público, con 
existencia legal y personería jurídica, integradas por familias que habitan y controlan determinados territorios, ligadas por vínculos ancestrales, sociales, económicos y culturales, expresados en la propiedad comunal de la tierra, el trabajo comunal, la ayuda mutua, el gobierno democrático y el desarrollo de actividades multisectoriales, cuyos fines se orientan a la realización plena de sus miembros y el país. (Art. $2^{\circ}$ de la Ley de Comunidades Campesinas - Ley N ${ }^{\circ}$ 24656). Las Comunidades Nativas tienen su origen en los grupos tribales de la Selva y Ceja de Selva y están constituidas por conjuntos de familias vinculadas por los siguientes elementos principales: idioma o dialecto, caracteres culturales y sociales, tenencia y usufructo común y permanente de un mismo territorio, con asentamiento nucleado o disperso. (Art. $8^{\circ}$ de la Ley de Comunidades Nativas y de Desarrollo Agrario de las Regiones de la Selva y Ceja de Selva - Decreto Ley No 22175). Según COFOPRI al 2010 se tiene 6,069 comunidades campesinas reconocidas con 1'084,738 familias (alrededor de 4.5. millones de personas, de las cuales están tituladas 5,110; las comunidades nativas reconocidas son 1469 reconocidas con 52,197 familias (alrededor de 260,000 personas), de las cuales están tituladas 1271. (Castillo, 2013).

Entidad Asociativa Agraria: Según el Dec. Leg. $\mathrm{N}^{\circ}$ 1020: Decreto Legislativo para la Promoción de la Organización de los productores Agrarios y la Consolidación de la propiedad Rural para el Crédito agrario, es la organización de productores agrarios conformada por dos o más productores que desarrollan actividad agraria o pecuaria en 20 o más hectáreas de tierra o por 10 o más productores agrarios independientemente de la extensión de las tierras en las que desarrollen dichas actividades.

Redes verticales o desarrollo de proveedores: En el Perú, el Programa de Desarrollo de Proveedores-PDP es un mecanismo de promoción de la integración de las pequeñas y medianas empresas a las cadenas productivas industriales, comerciales y de servicios de las grandes empresas de nuestro país. Este Programa busca identificar a las grandes empresas nacionales e interesarlas en desarrollar la competitividad de sus proveedores, los cuales verán potenciadas sus fortalezas a través de un plan de mejoras conducentes a incrementar su capacidad de respuesta en calidad, precios, plazos de entrega y servicio, ante los requerimientos de sus clientes. El desarrollo de proveedores beneficia no solamente a las pequeñas y medianas empresas, también favorece a las empresas cliente y al país en general. Los beneficios al cliente (gran empresa) se traducen en reducciones de costo de no-calidad, de abastecimiento y de transporte y desaduanaje. Lo anterior los lleva a ser más competitivos en sus respectivos mercados y a estar mejor facultados para satisfacer las exigencias de sus propios clientes.
Redes horizontales o consorcios: El consorcio es un contrato por medio del cual dos o más personas se asocian para desarrollar uno o varios negocios. El Consorcio se encuentra regulada en la Ley 26887 denominada "Ley General de Sociedades" que está vigente desde hace más de 10 años. Esta Ley brinda a las personas, distintas alternativas para poder trabajar unidas y, una de esas alternativas es el consorcio. Sus principales características son: consta por escrito, no nace una persona jurídica, no se inscribe en los Registros Públicos y cada integrante mantiene la propiedad de sus bienes y su independencia. Un consorcio puede servir para muchas cosas, pero en el caso concreto, servirá para: efectuar compra de insumos o contratar servicios en común y efectuar la venta de la producción en común.

Sociedad agrícola de interés social-SAIS: Este modelo asociativo fue creado mediante el Decreto Ley 17716 del 24 de Junio de 1969: Ley de reforma agraria, y se define como: "personas jurídicas de derecho privado y responsabilidad limitada, integradas por beneficiarios de la ley de reforma agraria, que se constituyen cuando la Dirección general de reforma Agraria y asentamiento Rural lo considera necesario y se rigen por los principios básicos de las sociedades de personas y del sistema cooperativo."

Sociedad Anónima: Es una sociedad de capitales con responsabilidad limitada, en la que el capital social se encuentra representado por títulos negociables y que posee un dinamismo jurídico propio y dinámico orientado a separar la propiedad de la administración de la sociedad. El mínimo de socios es de 2 y máximo de 750 personas. El patrimonio personal de los socios no está afecto. La sociedad anónima es la forma de organización que presenta mayor dificultad para adoptarse, debido a los objetivos que generalmente persiguen los pequeños productores agrícolas.

Unión de Crédito y Ahorro -UNICA: Forma de organización que surge del Programa Inclusivo de Desarrollo Empresarial Rural - PRIDER - de COFIDE, que tiene la finalidad de mejorar las condiciones de vida de las familias de zonas rurales en situación de pobreza a través de su inclusión eficiente y sostenible en el mercado. Las Unicas son asociaciones multifamiliares conformadas por 10 a 30 familias que se seleccionan mutuamente en base al conocimiento y la confianza. Brindan servicios de créditos y ahorro para sus asociados. La UNICA es una escuela empresarial, en las que se internalizan los principios de la acumulación de capital de la operación de la economía de mercado, que orientarán a las familias de productores a maximizar la rentabilidad mediante el uso competitivo, eficiente y sostenible de sus recursos. La asociación productiva, es la forma a través de la cual los socios de la UNICA pueden incursionar en actividades productivas, contando con la asesoría y seguimiento especializado. 
Empresas de Accionariado Campesino (EAC): Son sociedades anónimas convencionales cuyo capital social mayoritario es aportado por unidades familiares provenientes de las UNICAS. Estas empresas se crean con la finalidad de realizar actividades comercializadoras, empacadoras, acopiadoras o hacer más rentable la producción, dándole mayor valor agregado. Las familias asociadas cuentan para su capital de trabajo con las UNICAS. Además pueden acceder a los productos financieros estructurados-PFE de COFIDE u otras líneas de financiamiento para realizar sus inversiones. Para acrecentar su capital, asegurar mercados y acceder a conocimientos tecnológicos, las EAC tienen la posibilidad de asociarse con grandes y medianos empresarios.

Cabe destacar que, independientemente de la figura legal de organización que decidan adoptar, los pequeños productores agrícolas, lo más importante es que la organización se gestione con eficiencia y eficacia desarrollando ventajas competitivas y rentabilidad de manera sostenible.

Evaluación de la cadena de valor de pequeños productores agrícolas.

Las actividades de la cadena de valor evaluadas mediante encuesta de los pequeños productores agrícolas se muestran en la tabla 2 siguiente.

Tabla 2. Eficiencia de la cadena de valor de pequeños productores agrícolas.

\begin{tabular}{lcccc}
\hline $\begin{array}{l}\text { Actividades de la } \\
\text { Cadena de valor }\end{array}$ & $\begin{array}{c}\text { Bueno } \\
(1)\end{array}$ & $\begin{array}{c}\text { Regular } \\
(0.5)\end{array}$ & $\begin{array}{c}\text { Malo } \\
(0.25)\end{array}$ & $\begin{array}{c}\text { Inexistente } \\
(0)\end{array}$ \\
\hline Actividades & & & & \\
Primarias & & & & \\
Logística interna & 17 & 39 & 44 & 0 \\
Producción & 25 & 68 & 7 & 0 \\
Logística externa & 16 & 23 & 35 & 0 \\
Marketing y Ventas & 0 & 8 & 33 & 59 \\
Servicios & 7 & 36 & 45 & 12 \\
Actividades de & & & & \\
Apoyo & 11 & 65 & 24 & 0 \\
Infraestructura & 7 & 71 & 22 & 0 \\
Gestión de recursos & & & 43 & 42 \\
humanos & 7 & 8 & 43 & 0 \\
Desarrollo de & 31 & 63 & 7 & 113 \\
tecnología & 121 & 381 & 260 & \\
Compras & & &
\end{tabular}

Cálculo de la Eficiencia promedio de la Cadena de valor $\mathrm{E}=\underline{121+381(0.5)+260(0.25)}=\underline{376.5}=0.4303=$ $43 \%$ 875 875

$\mathrm{D}=1-0.4303=0.5697=57 \%$

Donde: $\mathrm{E}=$ Eficiencia, $\mathrm{D}=$ Deficiencia $\mathrm{n}=\mathrm{N}^{\mathrm{o}} \mathrm{de}$ factores o elementos analizados.

Fuente: Elaboración propia.
En la tabla 2 se observa que, de acuerdo con las respuestas de los 100 pequeños productores agrícolas encuestados, la eficiencia promedio que logran en el desarrollo de las actividades de valor es del $43 \%$, cifra por debajo del promedio, que revela que ellos no poseen conjuntamente capacidades que constituyen ventajas competitivas significativas. De manera similar, complementando el análisis en la tabla 03 siguiente, se muestran los valores obtenidos en relación a los otros factores que forman la ventaja competitiva: calidad, capacidad de innovación y servicio al cliente.

Tabla 3. Eficiencia de la calidad, capacidad de innovación y servicio al cliente.

Metas de Bueno Regular Malo Inexistente generación de valor (1) (0.5) (0.25) (0)

\begin{tabular}{lcccc}
\hline Calidad & 18 & 71 & 11 & 0 \\
Capacidad de & 7 & 8 & 43 & 42 \\
innovación & 7 & 36 & 45 & 12 \\
Servicio al cliente & 7
\end{tabular}

Cálculo de la Eficiencia promedio de la Cadena de valor

$\mathrm{E}=\underline{18+71(0.5)+11(0.25)}=\underline{56.25}=0.5625=56 \%$

$$
100 \quad 100
$$

$\mathrm{E}=\underline{7+8(0.5)+43(0.25)}=\underline{21.75}=0.2175=22 \%$

$\mathrm{E}=\underline{7+36(0.5)+45(0.25)}=\underline{100} \underline{\underline{36.25}}=0.3625=36 \%$

$$
100 \quad 100
$$

Fuente: Elaboración propia

Las cifras que se aprecian en la tabla 3, señalan que el nivel de eficiencia en cuanto a calidad de productos y procesos es del $56 \%$, de capacidad de innovación $42 \%$ y de servicio al cliente $36 \%$.

\section{Factores que favorecen la asociatividad de los pequeños productores agrícolas.}

En cuanto a los factores que favorecen la asociatividad de los pequeños productores agrícolas de los departamentos estudiados: Ayacucho, Cuzco, Ica, Junín, Lambayeque, Lima, Piura y Tumbes producto de las encuestas realizadas a éstos, considerando el nivel de importancia de los factores en una escala de 1 a 5 , se obtuvieron los resultados que se aprecian en la tabla 4 siguiente. Tambien, se observa que los factores con porcentajes más significativos en nivel de importancia 4, que favorecen la asociatividad de los pequeños productores agrícolas son: Costumbre de trabajo comunal (75\%), acceso a mercados (72\%), captación de recursos financieros $(71 \%)$ y reducción de costos en nivel 3 (66\%). Factores considerados con menor importancia, en nivel 2, fueron: optimización de la calidad $(66 \%)$, poder de negociación con clientes y proveedores (64\%) e incorporación de tecnología (61\%). 
Tabla 4. Factores que favorecen la asociatividad de los pequeños Productores agrícolas.

\begin{tabular}{|c|c|c|c|c|c|}
\hline \multirow{2}{*}{ Factor } & \multicolumn{5}{|c|}{ Nivel de importancia } \\
\hline & 1 & 2 & 3 & 4 & 5 \\
\hline $\begin{array}{l}\text { Mayores beneficios } \\
\text { económicos }\end{array}$ & 3 & 68 & 11 & 10 & 8 \\
\hline Mayores beneficios sociales & 4 & 15 & 65 & 9 & 7 \\
\hline $\begin{array}{l}\text { Costumbre de trabajo } \\
\text { comunal }\end{array}$ & 2 & 3 & 12 & 75 & 8 \\
\hline Reducción de costos & 3 & 14 & 66 & 8 & 9 \\
\hline $\begin{array}{l}\text { Poder de negociación con } \\
\text { clientes y proveedores }\end{array}$ & 5 & 64 & 14 & 11 & 6 \\
\hline Incorporación de tecnología & 7 & 61 & 17 & 10 & 5 \\
\hline Optimización de la calidad & 2 & 66 & 13 & 15 & 4 \\
\hline $\begin{array}{l}\text { Captación de recursos } \\
\text { financieros }\end{array}$ & 5 & 7 & 11 & 71 & 13 \\
\hline Riesgos compartidos & 7 & 12 & 63 & 11 & 7 \\
\hline Acceso a mercados & 1 & 6 & 8 & 72 & 13 \\
\hline
\end{tabular}

Fuente: Elaboración propia

Factores que dificultan la asociatividad de los pequeños productores agrícolas.

En cuanto a los factores que dificultan la asociatividad de los pequeños productores agrícolas de los departamentos de: Ayacucho, Cuzco, Ica, Lambayeque, Lima, Piura y Tumbes, producto de las encuestas realizadas a éstos, considerando el nivel de importancia de los factores en una escala de 1 a 5 , se obtuvieron los resultados que se muestran en la tabla 05 siguiente.

Tabla 5. Factores que dificultan la asociatividad de los pequeños productores agrícolas.

\begin{tabular}{|c|c|c|c|c|c|}
\hline \multirow{2}{*}{ Factor } & \multicolumn{5}{|c|}{ Nivel de importancia } \\
\hline & 1 & 2 & 3 & 4 & 5 \\
\hline $\begin{array}{l}\text { Desconocimiento de formas de } \\
\text { asociatividad }\end{array}$ & 4 & 8 & 10 & 69 & 9 \\
\hline Rechazo a la asociatividad & 5 & 7 & 13 & 66 & 9 \\
\hline $\begin{array}{l}\text { Falta de capacitación y } \\
\text { educación }\end{array}$ & 3 & 4 & 63 & 25 & 5 \\
\hline Desconfianza & 1 & 5 & 12 & 71 & 11 \\
\hline $\begin{array}{l}\text { Preferencia por trabajo } \\
\text { individual }\end{array}$ & 11 & 64 & 14 & 6 & 5 \\
\hline $\begin{array}{l}\text { Baja capacidad de gestión } \\
\text { asociada }\end{array}$ & 7 & 60 & 18 & 9 & 6 \\
\hline Temor al fracaso & 2 & 66 & 13 & 15 & 4 \\
\hline Esperanza de ayuda del Estado & 3 & 6 & 11 & 69 & 11 \\
\hline $\begin{array}{l}\text { Evitar controlar } \text { y } \\
\text { controlado }\end{array}$ & 6 & 10 & 62 & 14 & 8 \\
\hline Bajos estándares de calidad & 1 & 67 & 16 & 11 & 5 \\
\hline
\end{tabular}

Fuente: Elaboración propia

En la tabla anterior 5, se puede apreciar que los factores más significativos, en nivel 4 de importancia, que dificultan la asociatividad de los pequeños productores agrícolas son: Desconfianza (71\%), esperanza de ayuda del Estado (69\%), desconocimiento de formas de asociatividad (69\%) y rechazo de la asociatividad (66\%). Factores considerados con menor importancia, en nivel 2, fueron: bajos estándares de calidad (67\%), temor al fracaso $(66 \%)$, preferencia por el trabajo individual (64\%) y baja capacidad de gestión asociada, (60\%).

\section{Casos de asociatividad de pequeños productores agrícolas.}

De las formas de asociatividad analizadas, casos que obtuvieron un éxito considerable son las asociaciones y las cooperativas. Entre estas se encuentran la Asociación de Pequeños Productores de Banano Orgánico de Saman y Anexos-APPBOSA, y la Cooperativa Agraria Cafetalera La Florida. En cadenas productivas se tiene a la: cadena de producción de papa capiro para la elaboración de hojuelas del Valle del rio Chillón de Lima. En el caso de las comunidades campesinas, por su antigüedad y los principios en la crianza de la agrobiodiversidad se destaca la Comunidad campesina de Quispillaccta. Un caso de clúster lo constituye el Instituto Peruano de la Alpaca y los camélidos y caso importante de sociedad agrícola de interés social-SAIS es la Túpac Amaru. En cuanto a las uniones de crédito y ahorro-Únicas se tiene a la red de Uniones de Crédito y Ahorro-UNICAS de Lambayeque.

La Asociación de Pequeños Productores de Banano Orgánico de Samán y Anexos - APPBOSA: Se fundó el 5 de Febrero del año 2003 gracias a la unión de 98 pequeños productores y desde entonces ha venido creciendo hasta llegar a los 331 asociados con los que cuenta actualmente. APPBOSA es la asociación de productores de banano orgánico más grande del Perú y con el apoyo de Fairtrade Labelling Organizations Internacional-FLO (Organización Internacional de Comercio Justo), fue pionera en obtener la certificación orgánica de sus campos, fue la primera organización que logro procesar la fruta de sus asociados en el 2006 e igualmente la primera en obtener la certificación Global gap en el 2007 y la exportación directa en el 2008. Con su producto bandera el banano orgánico, ha logrado alcanzar mercados principalmente europeos. Sus áreas de cultivo superan las 400 hectáreas y todas tienen riego tecnificado.

\section{Cooperativa Agraria Cafetelera La Florida.}

La Cooperativa La Florida fue fundada en 1966, se encuentra ubicada en la Región Junín, provincia de Chanchamayo, distrito de Preñi. En la actualidad, la cooperativa es miembro de la Junta Nacional del Café, así como también son accionistas mayoritarios de la empresa Corporación Productores Café del Perú SAC. La actividad principal de la cooperativa es la comercialización del café, pero también posee otras como la transferencia de tecnología, capacitación, educación o salud. Cuenta con 1200 socios productores cafetaleros, de los cuales aproximadamente el $80 \%$ son varones y el $20 \%$ mujeres. Alrededor del $95 \%$ de la producción de La Florida se exporta a mercados de la Unión Europea, Japón, Estados Unidos, Canadá y Corea. Tienen su 
propia área financiera llamado Crediflorida, que apoya directamente el financiamiento y sostenimiento de los productores. Además, ha desarrollado programas productivos de diversificación productiva, asistencia técnica y agroindustrial. También posee un Centro de Educación llamado: Centro Educativo Ocupacional para Agricultura Sostenible- CEOAS, donde se imparten temas relacionados con salud, tecnología agrícola, género, gestión y convivencia familiar.

La cadena de producción de papa capiro para la elaboración de hojuelas del valle del rio Chillón de Lima: Cadena promovida por la ONG Fomento para la Vida-FOVIDA, inicia intervenciones orientadas a la promoción del desarrollo de la pequeña agricultura en el año 1996. Sus acciones se concentraron en 4 Centros Poblados del Valle del Chillón asentados en la parte media baja de dicho valle, en los distritos de Carabayllo de Lima Metropolitana y Santa Rosa de Quives de la Provincia de Canta del Departamento de Lima; desarrollando las capacidades organizativas y técnico productivas de 103 parceleros, para elevar su productividad y que su asociatividad que les permitiera lograr economías de escala, para que se articularan competitivamente a mercados dinámicos, para el caso, con la empresa compradora -subsidiaria de Pepsico Internacional- cuyo producto principal son las papas en chips. La propuesta de asociatividad lograda en el Valle del chillón les ha permitido recobrar confianza a los agricultores, a una experiencia de comercialización de mayor escala, con un nuevo cliente que establece criterios de calidad; que les permite contar con un precio fijo y mayor al que pueden obtener en el mercado tradicional.

La comunidad campesina de Quispillaccta: Adquirió su reconocimiento como persona jurídica el año 1944. Es una de las comunidades más extensas del departamento de Ayacucho con una extensión 21,000 Hás (incluidas tierras de pastizales, bosques y tierras eriazas), localizada del distrito de Chuschi, Provincia de Cangallo, Departamento de Ayacucho, a una altitud que oscila entre los 2,700 y 4,300 metros sobre el nivel del mar. Cuenta con 3985 familias y tiene registrada empresa de radio televisión premiada por la UNESCO. En su Plan de conservación de la biodiversidad, su visión estratégica declara: "Los quispillacctas, como hijos de la Madre Tierra, criados por la Madre Semilla (Kawsaymamawan kawsaq) y como un pueblo mentado nivel de la Región por nuestra organicidad y otras formas de vivir, vivimos amparándonos fraternalmente (mana qanakuspa) y unidos en nuestra diversidad de sentimientos, criando en nuestras chacras, kanchas y en el paisaje (purun) todo cuanto existe, y respetuosos de otras formas de vivir y sentir, estamos orientados a recuperar el "allin kawsakuy" ("vivir bien") y el buen gobierno en nuestra comunidad".
El Instituto Peruano de la Alpaca y Camélidos, un típico cluster geográfico, en poco tiempo ha agrupado a un buen segmento de los miles de micro criadores de este camélido peruano, con notables éxitos. Ha logrado integrar una eficiente industria en toda la macro región sur del país -Arequipa, Cusco y Puno- a través de un agresivo plan estratégico basado en el establecimiento de normas de calidad, mejoramiento de la fibra, clasificación del desarrollo genético, censo alpaquero, información de precios, perfeccionamiento del abastecimiento y eliminación de intermediarios. Ha logrado una rigurosa clasificación de la fibra de alpaca de la amplia variedad existente: B1 (Extrafino/Baby) y Fs (Super fino). el IPAC genera, coordina y desarrolla propuestas técnicas para promover el desarrollo y la competitividad del sector con énfasis en los aspectos de: mercado, tecnología, empresa, organización, medio ambiente, biodiversidad y genética. El Instituto Peruano de la Alpaca y Camélidos busca la superación de los desequilibrios existentes entre los diferentes agentes que conforman la cadena productiva de la alpaca y otros camélidos, en base a una eficiente articulación productiva.

La Sociedad Agrícola de Interés Social- SAIS Túpac Amaru Ltda. $\mathbf{N}^{\circ}$ 1: En el marco de la reforma agraria se le adjudico 216,499 hectáreas a favor de la, el 24 Marzo de 1970 siendo reconocida oficialmente mediante Resolución Suprema $N^{\circ}$ 140-70 AG. Fue oficialmente constituida inicialmente por 16 Comunidades Campesinas: Usibamba, Tanta, Suitucancha, Huayhuay, Ondores, Huacapo, Urahuchoc, Paccha, Sacco, Llocllapampa, Chalhuas, Canchayllo, Huancaya, Huari, Pachachaca y Chacapalpa, y una cooperativa de Servicio de trabajadores “JUNIN" Ltda. $\mathrm{N}^{\circ}$ 224. La SAIS Tupac Amaru Ltda. Actualmente, está integrada por $30 \mathrm{mil}$ campesinos y mantiene la siguiente población ganadera: ovinos de raza Junín 120,000 cabezas, vacunos 3,500, alpacas 4,800 , vicuñas 4,500 , equinos 600 . Otras líneas de producción son: producción de $200 \mathrm{TM}$ de truchas por mes, 450 Hás. de pasturas sembradas a base de Rey grass y Trébol, centro de engorde, que anualmente se engorda 400 novillos de cruce Brown Swiss y producción de leche diaria de 2,000 litros de leche de los cuales elabora queso, yogurt, manjar blanco y mantequilla con tecnología de punta. Sin embargo, el Minag menciona que este modelo tiene más de cuatro décadas y ya no responde a la realidad, por lo que de la mano con el Ministerio de Agricultura (MINAG), buscan ingresar a la globalización económica, financiera y al mercado moderno para convertirse en una empresa de éxito. (Minag, 2012)

La red de Uniones de Crédito y Ahorro -UNICAS de Lambayeque. Es la federación regional de UNICAS cuyo propósito central es darle sostenibilidad a las uniones a través de capacitación, asesoría y supervisión. Además, desarrollan mecanismos de cooperación entre UNICAS tales como compras conjuntas de insumos o 
útiles escolares, venta de productos en bloque, labores de acopio y empaque, articulación con el mercado y otras. Pueden, asimismo, derivar en nuevos esquemas de asociatividad y/o de negocios; por ejemplo, en el caso de Lambayeque, en una cooperativa de ahorro y crédito de UNICAS. Según la Corporación Financiera de Desarrollo-COFIDE a la fecha se ha logrado: 5,150 familias asociadas a 350 UNICAS, con 4,500 has., aproximadamente de tierras en conjunto.

\section{DISCUSIÓN}

En general, la asociatividad empresarial es un proceso bastante complejo que posee una considerable gama de posibilidades pero siempre busca lograr el objetivo fundamental de unir recursos y capacidades para alcanzar el éxito conjunto. Las formas de asociatividad analizadas constituyen un elemento primordial del desarrollo de la agricultura y el logro de la competitividad que contribuyen efectivamente en la mejora de la calidad de vida de los pequeños y medianos productores. Por ejemplo, en el caso de la redes empresariales Amézaga y Artieda (2008), consideran que: "la asociatividad enfocada a hacer negocios entre productores agropecuarios es crucial para el desarrollo de la competitividad en el Perú, ya que repercutiría en una mejora de los ingresos y las condiciones de vida de gran parte de la población que se encuentra en condiciones de pobreza y pobreza extrema". Por otro lado, Elgue (2007) manifiesta que el asociativismo productivo posibilita salir del aislamiento y el individualismo y potenciar, al mismo tiempo, los recursos técnicos, económicos y humanos, a través de la sinergia del grupo. La escala asociativa permite el acceso a infraestructura, maquinarias y equipos y la optimización de las condiciones de negociación frente a acopiadores e intermediarios, así como también lograr bonificaciones en la compra de insumos y un acceso más fluido a la asistencia financiera. En cuanto, a la eficiencia promedio que logran conjuntamente en el desarrollo de las actividades de valor del $43 \%$, resulta una cifra debajo del promedio, que revela que trabajando individualmente los pequeños productores agrícolas no poseen recursos y capacidades que constituyan ventajas competitivas para sus negocios. Es por tal razón, que se reviste de gran importancia la acción que desarrolla el Minag para ayudarlos integrando a los pequeños productores y los campesinos de subsistencia en los mercados, prestándoles apoyo en materia de gestión de recursos naturales, control de calidad, transferencia de tecnología y mejora de la productividad para obtener mayor rentabilidad y una ventaja competitiva. (FIDA, 2013). Respecto a los principales factores que favorecen la asociatividad en apreciación de los pequeños agricultores encuestados: costumbre de trabajo comunal, mayores beneficios económicos, optimización de la calidad, acceso a mercados, captación de recursos financieros y reducción de costos, la alta valoración de costumbre de trabajo comunal y acceso a mercados, es similar a la encontrada por Maldonado (2012), en la Red de pequeños productores de banano orgánico comercio justo Perú. De igual modo, se puede apreciar respecto a los factores que dificultan la asociatividad: desconfianza, desconocimiento de formas de asociatividad, esperanza de ayuda del Estado y rechazo de la asociatividad, la valoración significativa de: rechazo de la asociatividad y desconfianza. Los factores que favorecen la asociatividad analizados en el estudio, no son factores fáciles de conseguir y por lo tanto la probabilidad de éxito de una organización asociativa resulta ser muy reducida; de igual modo los factores que la dificultan no son superables fácilmente. Sin embargo, los casos exitosos estudiados demuestren que las organizaciones asociativas pueden ser instrumentos muy valiosos de lucha contra la pobreza puesto que contribuyen de manera significativa en el mejoramiento de los ingresos de sus socios. En esta perspectiva, Tenorio (2010) manifiesta: "nosotros podemos demostrar que la pequeña agricultura sí es rentable, que los pequeños agricultores sí pueden incorporar tecnologías que usan insumos de bajo costo, y que para bajar sus costos de producción y acceder a mercados dinámicos y rentables lo único que tienen que hacer es asociarse. No es cierto que la única que tiene una opción de éxito sea la agricultura a gran escala. A su vez, Aguirre (2012), manifiesta que: aun hoy en día, muchos creen que la pequeña agricultura en el Perú es un lastre que nos heredó la Reforma Agraria de Velasco. No ha bastado con que más del $90 \%$ del café que exportamos provenga de pequeños productores y además de producir, exportan directamente su producto, no ha sido suficiente con que el boom exportador de banano orgánico peruano haya sido a partir de la asociatividad de los pequeños productores con más $50 \%$ de las exportaciones actuales de banano; a pesar de todos estos avances, y de otros muchos en diversos productos, aun muchos piensan que la pequeña agricultura en el Perú es un problema. En tal sentido, cabe mencionar lo manifestado por Víctor Manuel Noriega Toledo, Director General de la Dirección General de Competitividad Agraria del Minag: "Uno de los objetivos del Ministerio de Agricultura es promover la asociatividad entre los pequeños productores como una forma de integrarlos a la cadena agroexportadora y mantener a ese sector como uno de los más importantes por su impacto en la generación de empleo" (Perú orgánico, 2011).

\section{Conclusiones.}

La asociatividad es un sistema de organización que posibilita mejorar la competitividad de los pequeños productores agrícolas y las formas de ella predominantes en el país son: la asociación, la cooperativa y las comunidades campesinas y nativas; ubicándose en segundo orden: las cadenas productivas y clusters, redes empresariales verticales y horizontales o consorcios, sociedad agrícola de interés social-SAIS y Uniones de ahorro y créditos-UNICAS. Los factores que favorecen la asociatividad de los pequeños productores son: costumbre 
de trabajo comunal, mayores beneficios económicos, optimización de la calidad, acceso a mercados, captación de recursos financieros y reducción de costos. La eficiencia de la cadena de valor de los pequeños productores agrícolas alcanza un promedio de $43 \%$ que revela que conjuntamente no poseen conjuntamente capacidades que sean ventajas competitivas significativas. Los factores que dificultan la asociatividad de los pequeños productores agrícolas son: desconfianza, desconocimiento de formas de asociatividad, esperanza de ayuda del Estado y rechazo de la asociatividad. El país presenta experiencias exitosas de asociatividad de los pequeños productores agrícolas, entre las cuales se encuentran la Asociación de Pequeños Productores de Banano Orgánico de Saman y Anexos-APPBOSA, la Cooperativa Agraria Cafetalera La Florida, la cadena de producción de papa capiro para la elaboración de hojuelas del Valle del rio Chillón de Lima, la Comunidad campesina de Quispillaccta, el Instituto Peruano de la Alpaca y los camélidos, la sociedad agrícola de interés social- SAIS Túpac Amaru y la red de Uniones de Crédito y Ahorro-UNICAS de Lambayeque.

\section{Literatura citada}

Amézaga, C. y Artieda, L. 2008. Hacia un crecimiento con inclusión: la asociatividad como estrategia de desarrollo para las micro y pequeñas empresas agropecuarias en el Perú. APOMIPE. p. 15. Consultado: 27. nov. 2013. Disponible en:

http://www.apomipe.org.pe/codigo_php/imagenes/ download/Articulo TyTL final CAA $2008 \quad 1013$ bib. pdf

Aguirre, M. 2012. Apuntes sobre Asociatividad Agraria. Piura. Espacio Compartido. Consultado: 22. nov. 2013. Disponible en:

http://compartidoespacio.blogspot.com/2012/10/ apuntes-sobre-asociatividad-agraria.html

Castillo, P. 2013. Los retos del Minag para titular la propiedad comunal. Lima. CEPES. La revista agraria $\mathrm{N}^{\circ}$ 148, febrero del 2013. p.6. Consultado: 21. jun. 2013. Disponible en:

http://www.larevistaagraria.org/sites/default/files// revista/LRA148/LRA-148web.pdf

Elgue, M. y Chiariadía, C. 2007. Formas asociativas para la agricultura familiar, elementospara el análisis funcional y normativo de las distintas formas jurídicas. 1 a ed. - Buenos Aires. Prodernea/Prodernoa. p. 11.

FIDA (Fondo Internacional de Desarrollo Agrícola). 2013. Dar a la población rural pobre del Perú la oportunidad de salir de la pobreza. Roma. FIDA. p. 2. Consultado: 19. oct. 2013. Disponible en: http://www. ifad.org/operations/projects/regions/pl/factsheet/peru_s. pdf

EI Peruano. 1969. Decreto Ley 17716 del 24 de Junio de 1969: Ley de reforma agraria Lima. El Peruano. 24 de Junio de 1969.
El Peruano. 1978. Decreto Ley $N^{o}$ 22175: Ley de Comunidades Nativas y de Desarrollo Agrario de las Regiones de la Selva y Ceja de Selva. Lima. El Peruano. 10 de mayo de 1978.

El Peruano. 2000. Ley $N^{o} 24656$ Ley de Comunidades Campesinas. Lima. El Peruano. 22 de Julio del 2000. P. Pág. 190781.

Hill, CH. y Gareth, J. 2009. Administración estratégica. $8^{\mathrm{a}}$ edición. México. McGraw-Hill Educación. p.88.

INEI (Instituto Nacional de Estadística e Informática). 2013. Resultados definitivos IV Censo Agropecuario 2012. Lima. Instituto Nacional de Estadística e Informática. p.52

Maldonado, G. 2012. Determinantes e impacto de la asociatividad para el comercio justo: el caso de REPEBAN desde 2005 hasta 2010. Lima. Pontificia Universidad Católica del Perú-Facultad de Gestión y Alta Dirección. P. 100-102.

MINAG (Ministerio de Agricultura y Riego). 2012. Inversión en sociedad agrícola Túpac Amaru potenciará el desarrollo agropecuario de Junín. Lima. Minag. Unidad de Imagen Institucional. Consultado: 25 set. 2013. Disponible en: http://www.minag.gob.pe/portal/ casos/6901-inversion-en-sociedad-agricola.

Perú orgánico. 2011. MINAG promueve asociatividad para que productores formen parte de cadena agroexportadora. Perú orgánico, portal de agricultura orgánica. Consultado: 02. dic. 2013. Disponible en: http://www.peruorganico.com/blog/archives/562

Porter, M. 1991. Ventaja competitiva de las naciones. Vergara, BuenosAires, $1^{\text {a }}$ edición, 1990, 535 p., citado por GÓMEZ, L. 2011. Asociatividad empresarial y apropiación de la cadena productiva como factores que impulsan la competitividad de las micro, pequeñas y medianas empresas: tres tipos de caso. En Análisis, Asociatividad empresarial. Consultado: 21 feb. 2013. Disponible en:

http://www.pa.gob.mx/publica/rev_47/an\%C3\%A1lisis/ asociatividad_empresarial.pdf

PROYECTO CENTA-FAO. 2002. Asociatividad para mejorar el negocio agrícola, estrategia para el cambio. El Salvador. Ministerio de Agricultura y Ganadería Centro Nacional de Tecnología Agropecuaria y ForestalCENTA, Proyecto CENTA-FAO. p.9.

Tenorio, F. 2010. No es cierto que la agricultura a gran escala es la única que tiene una opción de éxito. La Revista Agraria 119, junio 2010 p. 10-11.

http://www.larevistaagraria.org/sites/default/files/revista/ r-agra119/LRA-119-4.pdf 